\title{
Intraoperative Hemodynamic Changes in Dexamethasone and Magnesium Sulphate as an Adjunct to Bupivacaine for Caudal Blockade Anesthesia and Analgesia in Children Undergoing Lower Abdominal Surgeries \\ Zeinab Ebrahim Ahmed Elhossary, Ghada Mohammed Ibrahim Abdelrazek, Abdalla Mohamed Goda, Hesham Hassan Shahadah* \\ Department of Anesthesia \& Surgical Intensive Care, Zagazig University, Zagazig, Egypt \\ *Corresponding author: Hesham Hassan Shahadah, E-mail: hhekima@gmail.com
}

\begin{abstract}
Background: It is possible to achieve caudal analgesia by administering a little amount of local anesthetic into the caudal canal. There have been good analgesic effects reported for Dexamethasone with Magnesium Sulfate. Objective: The aim of the work was to evaluate and compare between dexamethasone and magnesium sulphate regarding duration and first time of rescue analgesic requirement intraoperative and to measure intraoperative hemodynamic changes (MAP, HR, SPO2) sedation and the amount of sedative and analgesic required. Patients and Methods: Pediatric patients aged 2 to 6 years of both genders were included in this Randomized double blind clinical study. They were all scheduled for Lower Abdominal Surgeries. Before surgery, a computer-generated randomization table randomly assigned patients into two dexamethasone (D) and magnesium (M) groups, each were 20. Caudal block was administered to patients in Group D using dexamethasone $0.1 \mathrm{mg} / \mathrm{kg}$ in conjunction with bupivacaine $0.25 \%$ at $2 \mathrm{mg} / \mathrm{kg}$. Group M: patients received a 0.25 percent bupivacaine/magnesium sulphate caudal block of $5 \mathrm{mg} \mathrm{kg}$. The patients were submitted to clinical evaluation, laboratory investigations and monitoring pre and intraoperative hemodynamic changes. Results: Regarding demographic data, there was no significant difference between both groups $(\mathrm{P}>0.05)$. Regarding HR distribution at different times pre and intraoperatively, there was no significant difference between both groups ( $\mathrm{p}$ value $>0.05$ ). Regarding mean arterial blood pressure (MAP) at different times pre and intraoperatively, there was no significant difference between both groups ( $\mathrm{p}$ value $>0.05$ ). Regarding the arterial oxygen saturation at different times, there was no statistical significant difference between both groups ( $\mathrm{p}$ value $>0.05$ ). Conclusion: The analgesic profile of bupivacaine-induced caudal blocking children undergoing lower abdominal surgery was improved with magnesium $(5 \mathrm{mg} / \mathrm{kg})$ and Dexamethasone $(0.1 \mathrm{mg} / \mathrm{kg})$.
\end{abstract}

Keywords: Lower Abdominal Surgeries, Caudal Blockade Anesthesia and Analgesia, Dexamethasone, Magnesium Sulphate.

\section{INTRODUCTION}

A local anesthetic is injected into the caudal canal to create caudal analgesia. The sacral and lumbar nerve roots are thus blocked as a result. It is beneficial in the administration of analgesia following surgical procedures. This method is well-liked by young patients. Continuous caudal block can be treated with catheter insertion ${ }^{(\mathbf{1})}$.

When it comes to anesthetics, bupivacaine is classified as a pipecoloxylidide because it comes from the amide family. Bupivacaine is formed when a butyl group is attached to mepivacaine's piperidine nitrogen atom. Chiral drugs, like bupivacaine, have an asymmetric carbon atom ${ }^{(2)}$.

A powerful synthetic glucocorticoid, dexamethasone has just a little amount of mineralocorticoid action. It has 25-50 times the antiinflammatory and immunosuppressive effectiveness of hydrocortisone and can be up to 16 times more potent than prednisolone. A list of essential medicines for adults compiled by the World Health Organization includes this drug. This list encompasses both prescription and over-the-counter medications ${ }^{(3)}$.
Intravenous dexamethasone $(8-10 \mathrm{mg})$ has been shown to extend IV regional anaesthesia when used in conjunction with regional analgesia ${ }^{(4)}$.

Previous studies have indicated that intravenous dexamethasone can improve postoperative nausea and vomiting while preserving opioids in the early postoperative phase, between 24 and 48 hours after it is administered ${ }^{(5)}$.

Magnesium sulphate $\left(\mathrm{MgSO}_{4}\right)$ by virtue of $\mathrm{N}$ methyl-d-aspartate (NMDA) receptors antagonist property has been evaluated as an adjuvant to local anesthetics in the neuraxial blocks and peripheral nerve blocks ${ }^{(6)}$.

NMDA receptor blockage and a reduction in catecholamine release are responsible for some of magnesium's analgesic effects. Volatile anesthetics have the ability to lower their MAC (minimum alveolar concentration) by as much as $60 \%$ in laboratory investigations using rat models ${ }^{(7)}$.

The aim of the current work was to evaluate and compare between dexamethasone and magnesium sulphate regarding duration and first time of rescue analgesic requirement intraoperative and to measure intraoperative hemodynamic changes (MAP, HR, 
SPO2) sedation and the amount of sedative and analgesic required.

\section{PATIENTS AND METHODS}

This randomized, double-blind clinical study included a total of 40 ASA physical status classes I and II pediatric patients aged 2 to 6 years of both sexes scheduled for lower abdominal surgeries, attending at Anesthesia \& Surgical Intensive Care Department, Zagazig University Hospitals.

\section{Ethical Consideration:}

All children's parents gave their written approval, and the study was authorized by the Zagazig University Faculty of Medicine's research ethical committee The study was conducted in conformity with the Declaration of Helsinki, the world medical association's code of ethics for human subjects.

Inclusion criteria: Children aged $2-6$ years of both sexes, ASA I-II, undergoing elective lower abdominal surgeries, Body weight >10: <50-kilogram, Time of surgery $<2$ hours.

Exclusion criteria: Children with history of allergy to any of the study drug used, having coagulopathies, history of seizure or neurological deficit in lower limbs, or having local infection at site of block or anatomical malformation have been excluded from the study.

\section{Withdrawal criteria:}

The parents of the patients had the right to withdraw their patient from the study at any time without any negative consequences on medical or surgical treatment plane. An ineffective caudal block was determined by if the patient moved their limbs, had an elevated heart rate, or had a mean arterial pressure more than $15 \%$ of the baseline value.

Before surgery, a computer-generated randomization table randomly assigned patients into two magnesium (M) and dexamethasone (D) groups, each were 20.

Caudal block was administered to individuals in Group D using dexamethasone $0.1 \mathrm{mg} / \mathrm{kg}$ in conjunction with bupivacaine 0.25 percent $(2 \mathrm{mg} / \mathrm{kg})$.

Patients in Group M received a 0.25 percent caudal block using magnesium sulphate $5 \mathrm{mg} / \mathrm{kg}$ in combination with bupivacaine $2 \mathrm{mg} / \mathrm{kg}$.

\section{All the patients were subjected to the following:}

1. Thorough medical history taking from parents.

2. Physical examination: Chest and heart auscultation and back especial sacral examination.

3. Laboratory testing including complete blood count (CBC), random blood sugar, and coagulation profile (PT, PTT, INR).

The drugs for the caudal block were made by an anesthetic technician (a highly trained nurse) in sterile settings. There was no way to tell if a patient was in a group without their parents or guardians knowing. In Group D: $0.25 \%$ bupivacaine solution was injected into the epidural space at a dose of $2 \mathrm{mg} / \mathrm{kg}$ and $0.1 \mathrm{mg} / \mathrm{kg}$ of dexamethasone added to bupivacaine. Normal saline was added to mixture if required to make a total volume $1 \mathrm{ml} / \mathrm{kg}$. In Group M: $0.25 \%$ bupivacaine solution was injected into the epidural space at a dose of $2 \mathrm{mg} / \mathrm{kg}$ and $5 \mathrm{mg} / \mathrm{kg}$ magnesium sulphate added to bupivacaine. Normal saline was added to mixture if required to make a total volume $1 \mathrm{ml} / \mathrm{kg}$.

Sevoflurane was used to intubate the patient and induce anesthesia using a face mask and basic anesthetic monitoring (ECG, non-invasive blood pressure, SPO2, and capnography) (concentration of 8 percent in oxygen). The dorsum of the hand was inserted with an intravenous cannula (22-24 gauge) and secured. To make intubation easier, cisatracurium $(0.1$ $\mathrm{mg} / \mathrm{kg}$ ) was administered before inserting the endotracheal tube. One dosage of caudal block (standard loss of resistance technique) was performed with a 23-gauge needle on the patient in the lateral decubitus position. The kid was then shifted supine and anesthesia was maintained with isoflurane (concentration of $1: 1.5 \%$ corrected for age) in a gasoxygen combination (ratio of 1:1).

Hemodynamic and respiratory parameters are assessed intraoperatively at four study time points: mean arterial blood pressure, heart rate, and oxygen saturation $(\mathrm{SpO} 2)$. following surgical incision, 15 minutes post-operatively, 30 minutes later, and finally at the time of skin suture (t3). As a $15 \%$ drop or increase in MAP and HR from baseline, hypotension and bradycardia or hypertension and tachycardia were defined, treating it with: Oxygen $5 \mathrm{~L} / \mathrm{min}$, Atropine $0.01 \mathrm{mg} / \mathrm{kg}$, Ephedrine $2.25 \mathrm{mg} /$ incremental, and other measures Skin suturing is followed by a gradual IV infusion of paracetamol $(15 \mathrm{mg} / \mathrm{kg})$ before patients are moved to the postoperative recovery room while still unconscious.

\section{Statistical analysis}

Microsoft Excel was used to code, enter, and analyse data gathered from historical sources, basic clinical examinations, laboratory investigations, and outcome measurements. In order to perform statistical analysis, the data were imported into SPSS version 20.0 (Statistical Package for the Social Sciences).

The following tests were employed to determine the significance of differences based on the type of data: difference and association of qualitative variable by Chi square test; quantitative continues group represent by mean $\mathrm{SD}\left(\mathrm{X}^{2}\right)$. Quantitative differences between groups are examined using a $t$ test. $P$ value was set to 0.05 for outcomes that were significant, and to 0.001 for those that were highly significant.

\section{RESULTS}

Regarding demographic data, there was no significant difference between both groups $(\mathrm{P}>0.05)$ 
(Figure 1). Regarding HR distribution at different times pre and intraoperatively, there was no significant difference between both groups ( $\mathrm{p}$ value $>0.05$ ) (Table 1).

Regarding mean arterial blood pressure (MAP) at different times pre and intraoperatively, there was no significant difference between both groups ( $\mathrm{p}$ value $>0.05$ ) (Table 2).

Regarding the arterial oxygen saturation at different times, there was no statistically significant difference between both groups ( $\mathrm{p}$ value $>0.05$ ) (Table 3).
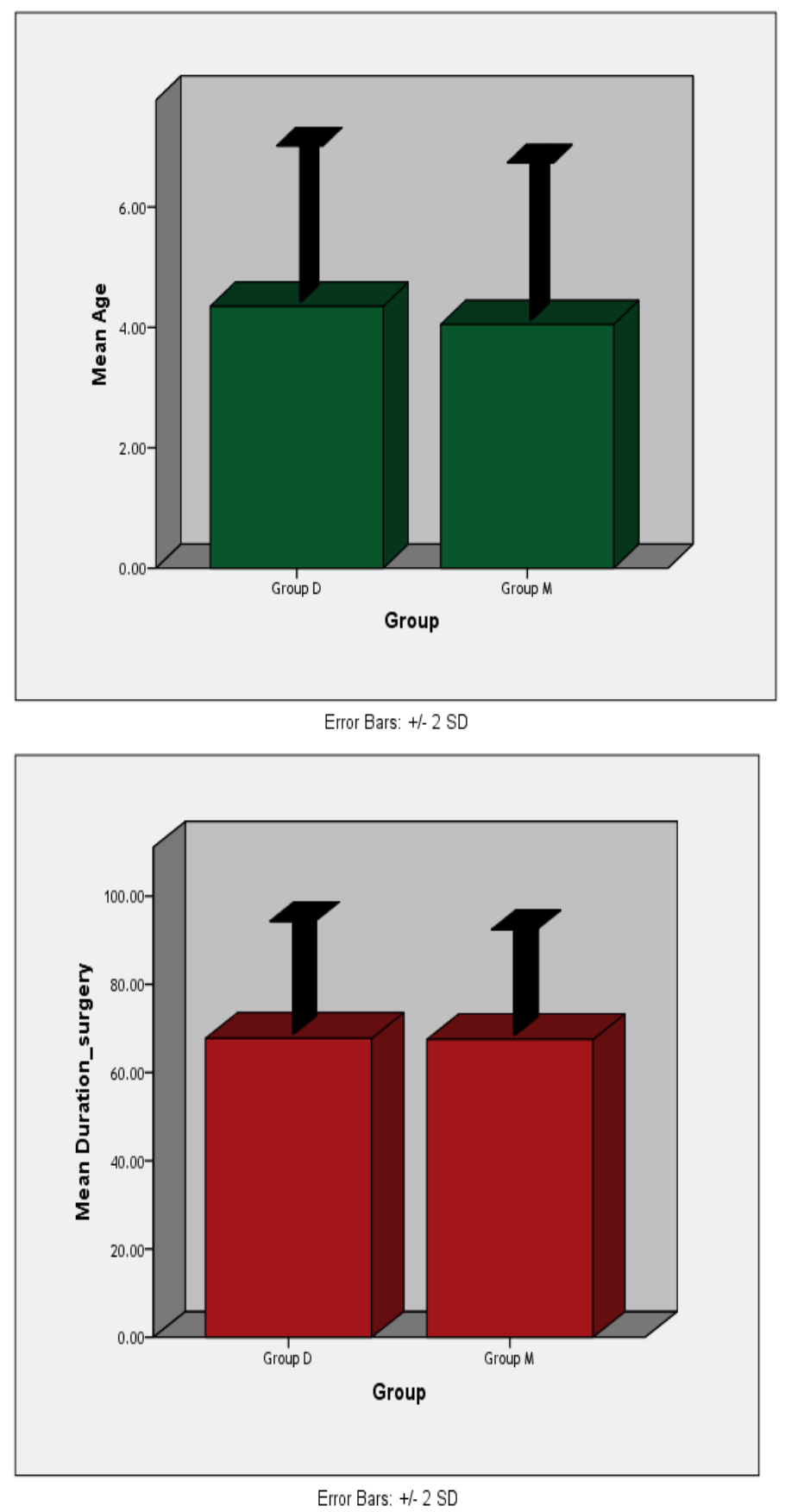

Fig. (1): Basic demographic and clinical characters of studied group
Table (1): HR distribution at different time's pre and intra $\mathrm{OP}$ among groups

\begin{tabular}{|l|c|c|c|c|}
\hline & $\begin{array}{c}\text { Group D } \\
(\mathbf{N}=\mathbf{2 0})\end{array}$ & $\begin{array}{c}\text { Group M } \\
(\mathbf{N}=\mathbf{2 0})\end{array}$ & $\mathbf{t}$ & $\mathbf{P}$ \\
\hline HR base line & $94.58 \pm$ & $93.75 \pm$ & 0.019 & 0.982 \\
& 6.99 & 7.01 & & \\
\hline HR & $97.55 \pm$ & $77.89 \pm$ & 0.029 & 0.980 \\
postsedation & 5.69 & 9.69 & & \\
\hline HR incision & $100.25 \pm$ & 101.05 & 0.031 & 0.978 \\
time & 8.45 & \pm 10.44 & & \\
\hline HR 15 min & $108.11 \pm$ & 109.01 & 0.015 & 0.988 \\
& 11.12 & \pm 10.65 & & \\
\hline HR 30 min & $102.54 \pm$ & $103.47 \pm$ & 0.051 & 0.968 \\
& 9.54 & 10.87 & & \\
\hline HR & $101.14 \pm$ & 102.655 & 0.048 & 0.969 \\
stitching & 7.25 & \pm 8.44 & & \\
\hline
\end{tabular}

Table 2: MAP distribution at different times pre and intraoperative among groups

\begin{tabular}{|l|c|c|c|c|}
\hline & $\begin{array}{l}\text { Group D } \\
(\mathbf{N = 2 0})\end{array}$ & $\begin{array}{c}\text { Group M } \\
(\mathbf{N}=\mathbf{2 0})\end{array}$ & t & P \\
\hline MAP base & 63.83 & 64.75 & 0.420 & 0.660 \\
line & \pm 2.62 & \pm 2.92 & & \\
\hline MAP post & 62.99 & 62.98 & 0.419 & 0.661 \\
sedation & \pm 2.21 & \pm 3.54 & & \\
\hline MAP & 61.58 & 61.11 & 0.421 & 0.654 \\
incision time & \pm 2.87 & \pm 2.58 & & \\
\hline MAP 15 min & 58.21 & 58.87 & 0.587 & 0.512 \\
& \pm 2.63 & \pm 2.92 & & \\
\hline MAP 30 min & 59.89 & 59.75 & 0.487 & 0.621 \\
& \pm 4.21 & \pm 2.22 & & \\
\hline MAP & 61.21 & 60.54 & 0.432 & 0.655 \\
stitching min & \pm 3.33 & \pm 2.01 & & \\
\hline
\end{tabular}

Table (3): SPO2 distribution at different times among groups

\begin{tabular}{|c|c|c|c|c|}
\hline & $\begin{array}{c}\text { Group } \\
\text { D } \\
(\mathbf{N}=\mathbf{2 0})\end{array}$ & $\begin{array}{c}\text { Group M } \\
(\mathbf{N}=\mathbf{2 0})\end{array}$ & $\mathbf{F}$ & $\mathbf{P}$ \\
\hline $\begin{array}{ll}\text { SPO2 } & \text { Base } \\
\text { line } & \end{array}$ & $\begin{array}{c}98.41 \pm \\
0.51\end{array}$ & $\begin{array}{c}98.58 \pm \\
0.52\end{array}$ & 0.419 & 0.661 \\
\hline $\begin{array}{l}\text { SPO2 post } \\
\text { sedation }\end{array}$ & $\begin{array}{c}98.87 \pm \\
0.41 \\
\end{array}$ & $\begin{array}{c}98.58 \pm \\
0.39 \\
\end{array}$ & 0.441 & 0.625 \\
\hline $\begin{array}{l}\text { SPO2 during } \\
\text { operation }\end{array}$ & $\begin{array}{c}98.93 \pm \\
0.55\end{array}$ & $\begin{array}{c}98.58 \pm \\
0.52 \\
\end{array}$ & 0.365 & 0.689 \\
\hline $\begin{array}{l}\text { SPO2 } \\
\text { stitching }\end{array}$ & $\begin{array}{c}99.16 \pm \\
0.26 \\
\end{array}$ & $\begin{array}{c}99.19 \pm \\
0.51 \\
\end{array}$ & 0.254 & 0.712 \\
\hline $\begin{array}{l}\text { SPO2 } \\
\text { immediately } \\
\text { post OP }\end{array}$ & $\begin{array}{c}99.11 \pm \\
0.39\end{array}$ & $\begin{array}{c}98.91 \pm \\
0.41\end{array}$ & 0.514 & 0.536 \\
\hline $\begin{array}{l}\text { SPO2 } \\
1^{\text {st }} \text { hour }\end{array}$ & $\begin{array}{c}98.87 \pm \\
0.87\end{array}$ & $\begin{array}{l}98.75 \pm \\
0.55\end{array}$ & 0.412 & 0.679 \\
\hline $\begin{array}{l}\text { SPO2 } \\
2^{\text {nd }} \text { hour }\end{array}$ & $\begin{array}{c}98.74 \pm \\
0.71 \\
\end{array}$ & $\begin{array}{c}98.36 \pm \\
0.65\end{array}$ & 0.418 & 0.662 \\
\hline $\begin{array}{l}\text { SPO2 } \\
4^{\text {th }} \text { hour }\end{array}$ & $\begin{array}{c}98.44 \pm \\
0.36\end{array}$ & $\begin{array}{l}98.41 \pm \\
0.25\end{array}$ & 0.417 & 0.663 \\
\hline $\begin{array}{l}\text { SPO2 } \\
8^{\text {th }} \text { hour } \\
\end{array}$ & $\begin{array}{c}98.98 \pm \\
0.74 \\
\end{array}$ & $\begin{array}{c}98.94 \pm \\
0.74 \\
\end{array}$ & 0.398 & 0.599 \\
\hline
\end{tabular}




\section{DISCUSSION}

Adjuvants such as opioids, ketamine, clonidine, and dexmedetomidine have been used to increase the duration of caudal analgesia after a single dose. However, unfavorable effects in children have restricted their use. Opioids have the potential to cause postoperative respiratory depression, while intrathecally administered ketamine can have neurotoxic effects ${ }^{(8)}$.

Caudal epidural blockade is widely used for various surgical operations either alone or as adjuvant with general anesthesia. The use of caudal additives like opioids and other various drugs has been used in children to improve or exaggerate the postoperative pain control but opioids were reported to induce many complications including depression of respiratory center, pruritus, urine retention and vomiting ${ }^{(9)}$.

Dexamethasone's hypnotic effect is mediated by noradrenergic neurons in the brain stem's locus coeruleus. The $\alpha-2$ adrenergic receptor inhibits adenylyl cyclase when active. Another catabolic cell activity is catalyzed by this enzyme, which results in the synthesis of cyclic AMP (cAMP). Because it lowers cellular cAMP levels, Dexamethasone promotes anabolic rather than catabolic pathways in cells. Calcium-activated potassium channels efflux potassium, and calcium channel entrance is inhibited in nerve terminals at the same time ${ }^{\mathbf{( 1 0 )}}$.

According to the results of another study, researchers are becoming increasingly interested in the analgesic properties of magnesium. The antinociceptive properties of this compound are due in part to its ability to control calcium influx into cells throughout the body. NMDA receptor blockade by magnesium, a physiological calcium antagonist, reduces nociceptive stimulation-induced central sensitization ${ }^{(11)}$.

According to the findings of the current study, no significant differences existed between the two groups in terms of demographic data $(P>0.05)$ that agreed with Elsonbaty (12) who concluded that regarding demographic characteristics there was no statistical difference between magnesium (Group M) and Dexamethasone (Group D).

Also, Yousef et al. (11) in their study, they included 105 children aged 1-6 years undergoing inguinal hernia repair who were members of the American Society of Anesthesiologists I and II. Researchers found no statistical difference between magnesium (Group M) and Dexamethasone (Group D) in terms of age, sex, and weight, with a mean age of 4.8 \pm 2.5 versus $4.5 \pm 2.6$.

The current study showed that there was no significant difference between groups D and group $\mathrm{M}$ regarding HR distribution at different times pre, intraoperatively which in agreement with the study of Elsonbaty ${ }^{(12)}$ They found no difference in heart rate between groups at baseline and after 10 minutes in terms of statistical significance. From 20 minutes to 120 minutes, there was a substantial difference in heart rate between the experimental groups and the control group.

While in contrast Milanjyoti et al. ${ }^{(13)}$ reported that the mean heart rates of group D were significantly lower than in Group M, the difference was statistically significant at different time's pre and intraoperative.

Compared to the control group, Bayoumy et al. ${ }^{(14)}$ found that the (D group) experienced a statistically significant decrease in HR after anesthetic induction, and at $15,30,60,90$, and 120 minutes intraoperatively and postoperatively; at the end of surgery; after extubation; and 30 minutes later if they were given a second dose of ketamine (M group).

The results of the current investigation revealed that there was no statistically significant difference between groups $\mathrm{D}$ and $\mathrm{M}$ in terms of mean arterial blood pressure (MAP) at various times before, during, and after surgery which in agreement with the study of Refaee et al. ${ }^{(15)}$ who reported that the baseline and postblock hemodynamic parameters (MAP) were comparable amongst the three groups. Group $\mathrm{M}$ and the other two groups revealed no difference in intraoperative hemodynamic readings in the post-hoc analysis; however, Group D had lower mean intraoperative readings than group $\mathrm{C}$.

After induction, there was no statistically significant difference between the two groups regarding MAP at baseline before the loading dose; at induction, then at 15,30 or 60 or 90 minutes; or after extubation; but after 30 minutes postoperatively, there was a statistically significant decrease in MAP among the (D group) 66.5 and 4.56 millimeters of mercury as compared to (M group) 73.11 and 4.74 millimeters of mercury $(\mathrm{p}=0.039)^{(\mathbf{1 4})}$.

According to the findings of this study, there was no significant difference in mean oxygen saturation (SpO2) between groups $\mathrm{D}$ and $\mathrm{M}$ at various intervals. According to Ali et al. ${ }^{(16)}$ there was no significant difference between the three study groups in terms of oxygen saturation monitoring during the intraoperative and postoperative periods.

\section{CONCLUSION}

It could be concluded that both magnesium (5 $\mathrm{mg} / \mathrm{kg})$ and Dexamethasone $(0.1 \mathrm{mg} / \mathrm{kg})$ improved the analgesic profile of bupivacaine-induced caudal block in children having lower abdomen surgery since both demonstrated good intraoperative hemodynamic alterations.

\section{RECOMMENDATION}

We recommend future studies with large sample in multicenter with different doses of drugs evaluate the effect of different doses on caudal blocks and to confirm our results.

Financial support and sponsorship: Nil. Conflict of interest: Nil. 


\section{REFERENCES}

1. Weber F, Wulf H (2003): Caudal bupivacaine and s (+)ketamine for postoperative analgesia in children. Paediatr Anaesth., 13 (3): 244-8.

2. Shah P, Upadhaya R, Kapoor $\mathrm{N}$ et al. (2016): A Comparative Clinical Study of Effect of Hyperbaric Levobupivacaine \& Bupivacaine for Spinal Anaesthesia in Patients Undergoing Elective Lower Abdominal \& Limb Surgeries. Indian Journal of Anesthesia and Analgesia, 7: 375-381

3. Williams D (2018): Clinical pharmacology of corticosteroids. Respiratory Care, 63(6): 655-670.

4. Bigat Z, Boztug N, Hadimioglu N et al. (2006): Does dexamethasone improve the quality of intravenous regional anesthesia and analgesia? A randomized, controlled clinical study. Anesthesia \& Analgesia, 102: 605-609.

5. De Oliveira J, Castro-Alves G, Ahmad L et al. (2013): Dexamethasone to prevent postoperative nausea and vomiting: an updated meta-analysis of randomized controlled trials. Anesthesia \& Analgesia, 116: 58-74.

6. Verma V, Rana S, Chaudhary S et al. (2017): A dosefinding randomised controlled trial of magnesium sulphate as an adjuvant in ultrasound-guided supraclavicular brachial plexus block. Indian Journal of Anaesthesia, 61: 250-255.

7. Elsharnouby N, Elsharnouby M (2006): Magnesium sulphate as a technique of hypotensive anaesthesia. BJA: British Journal of Anaesthesia, 96: 727-731.

8. El-Hennawy A, Abd-Elwahab A, Abd-Elmaksoud et al. (2009): Addition of clonidine or dexmedetomidine to bupivacaine prolongs caudal analgesia in children. British Journal of Anaesthesia, 103(2): 268-274.

9. Bharti N, Praveen R, Bala I (2014): A dose-response study of caudal dexmedetomidine with ropivacaine in pediatric day care patients undergoing lower abdominal and perineal surgeries: a randomized controlled trial. Pediatric Anesthesia, 24(11): 1158-1163.

10. Abd El Rahman A, Hassan K, Mohamed M (2017): Comparative Study Between Dexmedetomidine and
Magnesium sulfate Added to Bupivacaine In Spinal Anesthesia For Postoperative Analgesia In Patients Undergoing Perianal Surgeries. Sohag Medical Journal, 21(1): 183-189.

11. Yousef G, Ibrahim T, Khder A et al. (2014): Enhancement of ropivacaine caudal analgesia using dexamethasone or magnesium in children undergoing inguinal hernia repair. Anesthesia, Essays and Research, 8(1): 13-17.

12. Elsonbaty M (2017): Effect of intravenous magnesium sulphate or dexamethasone as adjuvants to sevoflurane anesthesia to prevent delirium during primary cleft palate repair, controlled randomized blind study. Egyptian Journal of Anaesthesia, 33(1): 91-95.

13. Milanjyoti P, Swaminathan A, Narayana B (2018): Comparison of Epidural Dexmedetomidine Vs Magnesium Sulphate used as Adjuvant to Ropivacaine for Analgesia in Post Thoracotomy patients: A prospective, controlled, double blind randomized study. Madras Medical College, Chennai. https://1library.net/document/eqod5ojz-comparisondexmedetomidine-ropivacaine-analgesia-thoracotomyprospective-controlled-randomized.html

14. Bayoumy A, Zeid G, El Deek A et al. (2020): Comparative study between magnesium sulphate and dexmedetomidine in controlled hypotension during functional endoscopic sinus surgery: a prospective randomized study. Ain-Shams Journal of Anesthesiology, 12(1): 1-9.

15. Refaee H, Elela A, Hanna $M$ et al. (2019): Dexmedetomidine versus Magnesium as Adjuvants to Bupivacaine-Induced Caudal Block in Children: A Randomized, Double-Blinded, Placebo-Controlled, Trial. Open access Macedonian Journal of Medical Sciences, 7(1): 73-77.

16. Ali A, Abu-Elwafa W, Rezk G et al. (2020): Comparison between Dexmedetomidine or Magnesium Sulfate as Adjuvants to Bupivacaine for Caudal Anesthesia in Pediatric Patients Undergoing Infraumbilical Surgeries. The Egyptian Journal of Hospital Medicine, 80(3): 1126-1137. 